\title{
Study on the Application of Educational Technology in Education Reform
}

\author{
Diqi Gao \\ Zhejiang University of Technology \\ Computer science and Technology College \\ Hangzhou,China \\ hz.yuanjian@qq.com
}

\author{
Qingshui Li \\ Zhejiang University of Technology \\ Computer science and Technology College \\ Hangzhou,China \\ mdusa@qq.com
}

\begin{abstract}
In order to make the education technology maximum extent to solve education are facing various problems, to adapt to the era of education development. Education technology becomes the key to realize education modernization, complete the teaching task, to improve teaching efficiency. In the current social situation, we should profoundly understand the important position of education technology in the education teaching as well as the necessity and urgency of the application, Fully understand application of education technology is the science and technology and social development of the requirement, also is the need of education reform and development. Adapt to the need of education reform and development, an very important is to rationally apply education technology to the education teaching.
\end{abstract}

Keywords- education technology; education reform; model; structure

\section{INTRODUCTION}

Since the 1990s, along with the multimedia technologies and the Internet new media popularization, mark the beginning of the fifth educational revolution. Educational technology obtained the rapid development, has become one of the most important driving force for the modernization education. Education technology is the medium of teaching information in the teaching process, in storage, transmission, processing teaching information. And the process of control and mastery knowledge plays an important role. This paper, by using relevant theories of philosophy, to analyze the essence of education technology and the dialectical view of the education technology of nature, Education technology is to satisfy the teaching of "learning" and "teaching" to use the physical and chemical technology and intelligent technology, human beings' cognition of the education and reform education embodies, is the medium that technical rationality in the field of education.

\section{EDUCATION TECHNOLOGY}

Education technology from broad sense and narrow sense two aspects to understand. From broadly, education technology refers to "education of technology", refers to the human in the education activities taken by the sum of all the methods and technical means. It is into invisible (smart form) and physical (materialized form) two kinds big. Smart technology is in the form of those in abstract form, in the form of function on the practice of scientific knowledge, such as system methods, etc Materialized form of technology refers to the solidification and the scientific knowledge is embodied in tangible material, including blackboard, chalk traditional teaching AIDS, is also included computers, satellite communications, etc all can be used in education, equipment, facilities, and the corresponding software.. From the narrow sense, education technology refers to solve various problems in the education and teaching in the use of all the media technology and system technology [1].

In the information age, the role of education technology is not only a auxiliary method in the education teaching, education technology is expanded constantly with the information technology development, has become the education reform and information the source and the commanding heights. Adapt to era development of education, education technology is the realization of education modernization, complete the teaching task, the key to improve teaching efficiency [2].

\section{THE STATUS OF EDUCATION REFORM}

Education is carried out in education ideology, teaching theory, learning theory and learning theory, Over the years with the teacher as the center occupies the dominant status in Chinese education, students passively and education mode. The traditional mode of education has many defects, education reform is imminent. At the present stage of the ongoing reform process, also highlights the many disadvantages [3]. Summarized as follows:

\section{A. Ignored the Reform of the Teaching Structure}

Education reform in recent years has made great achievements, but the sense that gives a person is the whole no big breakthrough in education reform. Main problem is that the educational reform focus on the content, means, and methods of reform, and ignore the transformation of teaching structure. Teaching structure is in a certain education thought, teaching theory and learning theory under the guidance, in a certain environment the stability of the structure form, the teaching activity process is the teachers, students, teaching materials and teaching media connect with each other, the embodiment of interaction.

\section{B. With the Teacher as the Center, the Students' Enthusiasm and Initiative is not enough}

The traditional education system is made up of teachers, students and teaching material of these three elements, under the modern teaching environment more add a element, is the teaching media. Teaching mode is the four elements connect with each other, interaction of the link. Through the relationship between four key elements: teachers teaching 
auxiliary, blackboard writing, and teaching media, convey the teaching content to students or should I say to instill in students. Teachers are the masters of the whole teaching process, students receive teacher instilled knowledge in a passive position. So pay attention to the established knowledge imparting skills, ignore students' initiative and enthusiasm, ignored the communication between students and teachers communication, ignore the exchanges and cooperation between the students.

\section{Ignore the Differences between Students}

Traditional education is static education, emphasizing the unity, the unity of teaching outline, teaching contents, training targets, teaching time, teaching place and evaluation criteria, ignoring the differences between the students, make the education become lifeless, lack of vitality. Emphasize the students' task is to digest, understand the teacher teach content, the students as an object of indoctrination, external stimulation of the receiver, the reservoir of previous knowledge and experience, forget a record is a subjective initiative of the students, creative thinking person [4].

\section{Application of EdUCATiOnal TeChNOLOGY IN THE TEACHING REFORM}

\section{A. Education Technologies Provides the Material}

\section{Foundation for the Education and Teaching Reform}

Promotion of educational technology enhances the advanced and superior of teaching methods. The development of modern education technology is advantageous for the updating of teaching media and teaching means modernization. A variety of media combination can be vivid to classroom teaching, education technology used to mobilize students' various senses feel in all aspects. Education technology popularization and application, enriched the education information resources. Through the adoption of multimedia teaching, can bring a greater amount of information into classroom, increase capacity, improve teaching efficiency. Multimedia illustrated, intuitive, vivid, has the expressive force of the traditional media can not reach, can the abstract concept of embodiment, makes the classroom teaching has entered a new stage.

\section{B. Education Technology Promotes the Reform of Education Mode}

Education technology popularization and application can promote the reform of education mode. In traditional education teaching the teacher is as the center, the students' solution in the subordinate position of teaching, lack of initiative and enthusiasm, passively accept what the teacher taught in the knowledge, To change all sorts of malpractices in traditional education, in accordance with the education thought, the theory and method, further explore the new teaching mode. To build a new mode of education thought is: education technology as support, reflect the goal of quality education, exert students' initiative in the learning process, initiative and creativity. Through the application of education technology is to build a new education teaching mode. The itself nature of educational technology determines its supporting role in the educational reform. Education in the teaching reform of the scientific technology, main sex, times, frontier and integral sex is to make it the breakthrough of education reform and the commanding heights [5].

\section{Education Technology Promoted the Reform of the Education Ideas}

Modern education thoughts and ideas is a theoretical basis of education technology. Teaching process is based on students as the main body, teacher as the leadership, teachers from teaching knowledge as the main design, from simply accept knowledge into students rely on self-study. The popularization and application of education technology, makes the concept gradually formed. Education technology research structure and effect of teaching and learning resources also pay attention to the study of the process of teaching and learning. The application of education technology not only the equipment purchase and software development, even more crucial is how to apply education technology, to explore and construct the new type of personalized teaching mode.

\section{Education Technology to Promote the Development of Quality Education}

Education technology is a kind of technical means, from teaching mode, transmission routes and class structure change, conducive to the cultivation of innovative talents. Education technology can promote the implementation of quality education, and with a quality education is inseparable. Education technology is under the guidance of the advanced education thought, applying advanced science and technology to the teaching, has a very important role in the cultivation of the talent.

\section{NEgAtive EFFECT OF MOdERn EdUCATION TECHNOLOGY APPLICATION}

The development of education technology, its way of thinking, is by the influence of technology tools and technology ontology. Technical tool theory is for education technology as a teaching tool, technology ontology theory for education as teaching environment. Theory of technical tool more widely, the influence of education technology professional teaching media has been for a long time as a research focus. Educational technology is the problem of education, but also a technical issue, it is a combination of education and technical problems. In practice, people often see it as a purely technical issue, ignoring the education system itself on the application of the technology of restriction and rejection. Education technology as a kind of technology also has its technology limitations. Technology is only a means, though developing rapidly in form, but the form is only realize the essential attribute of choice. Education technology application in the teaching exists many pitfalls [6].

1) Misunderstanding one: primary and secondary, teaching focus on teaching content, rather than fancy courseware 
Teaching the real goal should be to let the students understand and master the teaching content, the focus should be on the teaching content itself, multimedia is only secondary. Now part of the teacher does not pay attention to the teaching content itself, more pay attention to the form of multimedia courseware, courseware too flowery, makes students part's attention was attracted by the courseware, and don't have much energy to focus on the teaching content. So not only make the courseware using effect is poor, but also affect the teaching. When students can through the sensory stimuli into teaching courseware through thinking activity for the success of psychological content, the teaching courseware is the success courseware.

2) Misunderstanding two: courseware imbalanced. Good courseware the price is not high, low efficiency, poor courseware is time-consuming; echo what the books say, textbooks, teaching effect is not good.:

Application of education technology as the use of modern teaching means of multimedia teaching, courseware first considers the benefits. A good courseware it takes time is very much. Need a lot of pictures, animation, background music and so on material, need a lot of time to search and collect. If a class, lessons but it will take almost a month, even longer time; this will affect the whole progress of teaching.

3) Misunderstanding three: information overload and rambling

Information overload, display speed is too fast. Application of education technology, the use of modern teaching means of multimedia teaching, the biggest advantage is the large amount of information, convenient and quick. However, some teachers exert the advantages, making courseware; will be related to the text content of a large number of material lists. In teaching, the teacher easy to accelerate the rate of lectures, ignore with the pace of the students' thinking. Such courseware ignore focus and the focal points of teaching content, the advantages of rich content in the modern education technology into " modernization junk".

\section{The SCIENTIFIC AND RATIONAL USE OF MODERN TEACHING METHODS}

Teachers' application of education technology, the use of modern teaching means teaching, do not use, in order to use for teaching content services, and the organic integration of teaching process. Education technology in teaching learners and computer dialogue teaching methods, shift the continuity of learning for students, the ductility, need from students' psychological characteristics, teaching content, accords with the objective law of learners to accept knowledge, foster strengths and circumvent weaknesses, the content and form organic combination, can make all kinds of teaching means can complement each other, complement each other, improve the quality of teaching. Teachers' application of education technology, the use of modern teaching means teaching, to firmly establish the idea of "student-centered", pay attention to the information showing the speed and rhythm. Don't change too fast, the key position to be a pause, to give students time to digest and make notes. Consider students accept ability and the feedback situation, adjust to the demo content and schedule. Not abandon all the traditional education means but combine education technology and the traditional education means. Any kind of teaching media is not everything, big talk on education technology and modern teaching means and teaching all sorts of advantages at the same time, must not abandon traditional methods. We should of modern teaching technology and traditional teaching methods optimize combination, their respective advantages into full play.

According to the physical and mental characteristics of the students choose the multimedia, students' physical and mental characteristics of different learning levels, different ages of each not same, in the choice of multimedia to study with the specific circumstances of the students. Maximize the role and effectiveness of the multimedia, courseware demonstrate knowledge of the content must adapt to the teaching content with teaching materials, adapted to the students' cognitive level.

According to content choose the multimedia, student is the main body of classroom teaching, teachers are dominant, the multimedia auxiliary teaching effect. Whether to use multimedia in classroom teaching and how to use multimedia should be determined according to the teaching content. Teachers' application of education technology, the use of modern teaching means, the teaching input a stream of fresh wind, clever, activate the classroom, activate the teaching materials, activating teachers and students, the classroom teaching climax, rhythm and lively, layer upon layer, create a relaxed and happy learning atmosphere for students to create a learning environment is full of appeal, Let the student feel in the relaxed atmosphere of knowledge ocean of magic and mystery, so that they learn in the classroom, music in the classroom.

Education technology itself is neutral, theoretical system and research object with the progress of society and constantly enriches and perfect. Admittedly education technology in the education reform has important position and role as the core, but not the application of computer and network in education is to increase the education to a new level, to realize the modernization of education. Recognizing education as education technology neutrality, not blind faith in education technology can solve all the problems in education; don't put all hopes on education technology. According to the specific environment of education, education contents, the characteristics of education object, rational application of education technology, to achieve the ideal effect of education.

\section{CONCLUSIONS}

Education technology is for the implementation of the education and improves the effectiveness of education used methods, tools, and skills of the participants in the education combined. Education technology contains the education process and education resources in the design, development, utilization, management and evaluation, as well as to the technical training of the quality education participants. Educational technology is promoted the reform of the 
education. Education technology is widely used in teaching, greatly enriched the education information resources, the education technology of media and various basic Settings provides a material basis for the reform of education, School infrastructure, especially the establishment of the campus network and application, provides the material foundation for the education educational reform.

\section{REFERENCES}

[1] X.H.Deng, "To the philosophy of education technology research ," Modern education technology, 2010, vol. 2
[2] K.K.He, W.G. Li, “Educational technology ,"Beijing: Beijing Normal University press, 2002.

[3] Q.H.Ming, S.H. Cheng, "Education reform must break through the difficult points,"education reform subject self change; "Education theory and practice"2009-05-10

[4] Zh. Lv, "Teaching reform of modern education technology and the education relations thinking ," Higher education research, 2006, vol. 1

[5] G.L.Yang, "The modern education technology application in the field of vocational education teaching research ,"Dajin study master's thesis, 2005, vol. 1

[6] X.Y.Cha. , "The limitation of the education technology study ," Journal of electrochemical education research, 2008, (2) pp. 14-18 